Sains Malaysiana 50(12)(2021): 3523-3535

http://doi.org/10.17576/jsm-2021-5012-05

\title{
Surface Electromyography Quantification Methods for Evaluating Muscle Activity in Dysphagia
}

(Kaedah Kuantifikasi Elektromiografi Permukaan untuk Penilaian Aktiviti Otot pada Disfagia)

\author{
SUPRIJANTO*, AZIZAH S. NOOR, Miranti I. MANDASARI \& Hesty SuSANTI
}

\begin{abstract}
Quantitative evaluation of stroke patients with the risk of swallowing disorder or dysphagia is required to support diagnosis and further rehabilitation planning. Fluoroscopy X-ray imaging usually is used for swallowing diagnosis, though it gives radiation exposure to patients. Therefore, quantification of muscle coordination patterns involved in swallowing based on surface electromyography ( $S E M G)$ was introduced. However, an adequate quantification of sEMG for dysphagia diagnosis still lacks standardization. In this work, potential sEMG signal features, namely the contraction duration (DUR), the time to peak of maximum contraction (TTP), and the total RMS power (TP), were further investigated to evaluate the swallowing processes in healthy subjects and post-stroke patients. The experimental scheme instructed the participant, i.e. 20 healthy subjects and 20 patients, to swallow $3 \mathrm{~mL}$ of water in normal swallowing mode and swallow saliva in dry swallowing mode. The proposed signal processing procedure helps to establish the feature extraction of the three features mentioned earlier. For dysphagia assessment, with the support of our proposed signal processing procedure, DUR and TTP can be used together to improve diagnosis reliability. The characteristic of both features in healthy subjects was shorter than in post-stroke patients. Also, the TP feature is useful as additional information to evaluate the role of suprahyoid (SUP) and infrahyoid (INF) muscle groups which are very important in the swallowing process. These results are promising to provide a reliable set of features in the time domain for swallowing analysis. Notably, this can also be utilized as a feature for supporting the automatic classification of dysphagia diagnosis.
\end{abstract}

Keywords: Dysphagia; signals processing; surface electromyography (sEMG); swallowing disorder

\section{ABSTRAK}

Penilaian kuantitatif pesakit strok dengan risiko gangguan menelan atau disfagia diperlukan untuk menyokong diagnosis dan perencanaan rehabilitasi selanjutnya. Pengimejan sinar-X dengan kaedah fluoroskopi saat ini sering digunakan untuk diagnosis disfagia, walaupun ia menyebabkan pendedahan radiasi kepada pesakit. Oleh itu, kuantifikasi pola koordinasi daripada otot yang terkait pada proses menelan berdasarkan elektromiografi permukaan (sEMG) diusulkan. Walaupun demikian, standard kuantifikasi sEMG untuk diagnosis disfagia masih lemah. Dalam kajian ini, potensi ciri sEMG, antara lain durasi kontraksi (DUR), waktu ke puncak kontraksi maksimum (TTP) dan daya RMS total (TP) perlu dilakukan penilaian lebih lanjut untuk mengenal pasti proses menelan pada subjek yang sihat dan pasca penyakit strok. Skema uji kaji mengarahkan peserta yang terdiri daripada 20 subjek sihat dan 20 pesakit, untuk menelan $3 \mathrm{~mL}$ air dalam mod menelan normal dan menelan air liur dalam mod menelan kering. Prosedur pemprosesan isyarat yang diusulkan untuk menentukan ciri pengekstrakan daripada ketiga ciri yang disebutkan. Untuk penilaian disfagia, dengan prosedur pemprosesan isyarat yang diusulkan, DUR dan TTP dapat digunakan bersama untuk meningkatkan keberkesanan diagnosis. Kedua ciri pada subjek yang sihat adalah lebih pendek daripada pesakit pasca strok. Selain itu, ciri TP berguna sebagai maklumat tambahan untuk menilai peranan kelompok otot suprahoid (SUP) dan infrahoid (INF) yang sangat penting dalam proses menelan. Hasil daripada penelitian ini memberikan ciri untuk pengkelasan diagnosis automatik disfagia.

Kata kunci: Disfagia; elektromiografi permukaan (sEMG); gangguan menelan; pemprosesan isyarat 


\section{INTRODUCTION}

Swallowing is a daily activity for transporting food from the oral cavity to reach the stomach and prevent it from missing the airway. Swallowing dysfunction may be caused by the inability of muscle groups to conduct coordination. Swallowing dysfunction has been reported in about $44-63 \%$ of acute stroke patients. The swallowing disorder a stroke patient suffers is often called dysphagia (Kim et al. 2020; Sreedharan et al. 2020). Stroke patients with dysphagia tend to have a higher risk of pneumonia. The length of hospital stay in stroke patients with dysphagia is relatively longer than stroke patients without dysphagia (Baroni et al. 2012; Pacheco-Castilho et al. 2019).

Evaluation and diagnosis of stroke patients with the risk of dysphagia is a necessary initial step to treat dysphagia effectively and precisely. Quantitative evaluation and diagnosis are needed to improve accuracy in determining the suggestion of a rehabilitation scheme for patients (Saitoh et al. 2018). Some screening tests based on eating assessment performed by a qualified clinical person were reported with several test approaches, such as 10-item Eating Assessment (EAT 10), volume viscosity swallow test (VVST), and the Gugging Swallowing Screen (GUSS) (Benfield et al. 2020; Umay et al. 2019).

For the past years, video-fluoroscopic swallowing study (VFSS) has been accepted as the gold standard in evaluating and managing dysphagia, which leads to the development of an objective prognosis scale for dysphagia named video-fluoroscopic dysphagia scale (VDS). However, this scale still contains subjectivity because it is defined based on the clinician's qualitative assessment. Besides, it shows different correlation coefficients regarding its etiology. VFSS also has disadvantages due to its cost and radiation (Edmiaston et al. 2014; Miyashita et al. 2019; Rommel et al. 2015).

As an alternative, a bio-potential instrumentation system based on surface electromyography (sEMG) has been developed to support assessment in quantifying the severity of dysphagia in post-stroke patients. In comparison with VFSS, sEMG is a non-radiation and inexpensive technique. Despite extensive use of sEMG to study muscle coordination involved in the swallowing process, relatively little information is available regarding the reliability of SEMG signal features to support the swallowing process's quantification (Koyama et al. 2020; Saijo et al. 2017). The main problem of sEMG is electrode placement in a proper position. Some studies on sEMG focused on the single muscle or muscle pair activity (Archer et al. 2020; Giannantoni et al. 2016; Saijo et al. 2017).
This work aims to establish the processing steps for feature extraction of the quantification sEMG signal in the time domain. The sEMG signal features consisting of the contraction duration (DUR), the time to peak of maximum contraction (TTP), and the total root means square (RMS) power (TP) were evaluated to distinguish swallowing processes in healthy subjects and post-stroke patients. Due to the variability of raw sEMG signal among participants and signal contamination by noise and heart rate artifacts, the raw sEMG signal's processing scheme was also described. The proposed method was used to process the raw SEMG signals recorded from suprahyoid (SUP) and infrahyoid (INF) muscle groups. The output of raw sEMG signal processing was used for the feature extractions. The features were used to distinguish swallowing processes in healthy subjects and post-stroke patients. The experimental scheme instructed the participants to swallow $3 \mathrm{~mL}$ of water (normal swallowing) and saliva (dry swallowing). Three types of sEMG features were determined from the two types of swallowing tasks for healthy subjects. For the evaluation, the statistical analysis based on the mean and standard deviation of each task's feature was calculated to define specific parameters related to the participants' conditions. The paper is organized as follows: Next section describes the material and methods related to the participants and experimental protocol, sEMG measurement procedure, the methods of the proposed signal processing, and quantification procedure. Finally, the experiment results and conclusion are presented in the last section.

\section{MATERIALS AND METHODS}

PARTICIPANTS AND EXPERIMENTAL PROTOCOL

To evaluate the sEMG processing steps for swallowing assessment, sEMG signal recording in healthy and patient-participants. On the experimental protocol, sEMG was recorded during the participant's task: a voluntary swallow of $3 \mathrm{~mL}$ of water (normal swallowing) and saliva (dry swallowing). The experimental protocol consisted of two swallowing tasks, including a voluntary swallow of $3 \mathrm{~mL}$ of water (normal swallowing) and saliva (dry swallowing). All the swallowing tasks were conducted in three repetitions by the participants with a ten-second pause between each task. The Ethics Committee of Hasan Sadikin Hospital, Bandung approved this study protocol (approval no. LB.02.01/X.6.5/62/2019).

For the baseline sEMG signal characteristic, healthy participants with ages between $21 \pm 1.5$ years (10 men) are involved in the research. The licensed therapist 
examined all participants to make sure have no medical problems that might affect swallowing. For patients, 10 men and 10 women (age within $39.8 \pm 15.5$ years) are involved in the research. According to the medical record, the patients have a lesion in the brain stem and subcortical. Furthermore, a qualified clinical person was diagnosed that patients have the problem of speech communication and swallowing dysfunction.

\section{SEMG MEASUREMENT PROCEDURE}

For the swallowing process evaluation, disposable sEMG electrodes were attached to the suprahyoid (SUP) and infrahyoid (INF) muscle groups. The selection of these two muscle groups was based on their function. The SUP muscle group's function is to lift the hyoid bone and open the esophagus so that food boluses can pass through. In contrast, the INF muscle group function is to hold the hyoid and larynx bones when swallowing and speaking. The activities of two lateral SUP and INF muscle groups were measured simultaneously during the experiment, as shown in Figure 1. The positive electrodes were placed on the neck area related to SUP and INF muscle groups. The negative electrodes (reference electrodes) were placed in the innervation zone. The measurement was held using disposable surface EMG electrodes $\mathrm{Ag} / \mathrm{AgCl}$. The sEMG signal was recorded using FlexComp Infiniti encoder (Thought Technology, Montreal, Quebec, Canada with a sampling rate (Fs) of $2048 \mathrm{~Hz}$.

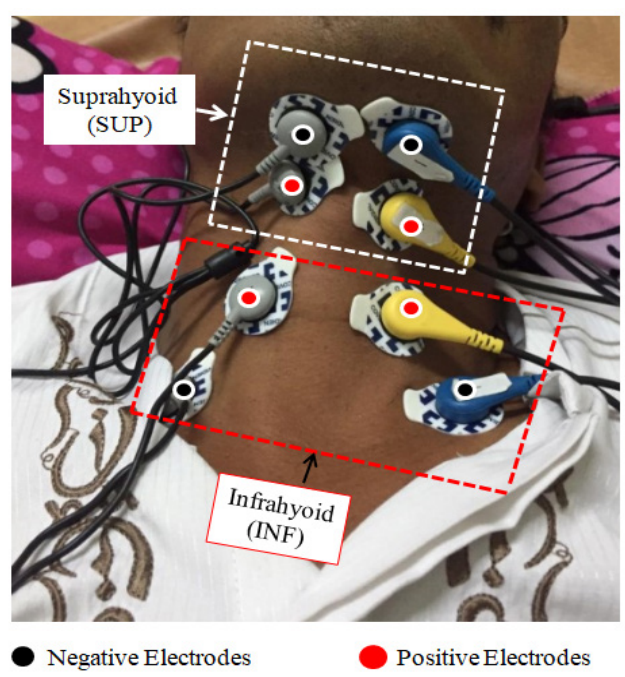

FIGURE 1. The illustration of the placement of SEMG electrodes in the left and right suprahyoid (SUP) and infrahyoid (INF) muscles, i.e., four positive electrodes (active electrodes) and four negative electrodes (reference electrodes)

The examples of recorded raw sEMG signals from post-stroke patients with dysphagia was shown in Figure 2. The raw sEMG signals were recorded from the patients under the dry swallowing task in three repetition tasks. The typical ECG signal artifact is shown in Figure 2, particularly in the raw sEMG $\left(\mathrm{S}_{\mathrm{RAW}}(\mathrm{n})\right)$ in the right INF (INF-R) marked with the red arrow.

\section{SEMG SIGNAL QUANTIFICATION}

The electrodes attached on the right and left sides of SUP (denoted by SUP-R and SUP-L) and on the right and left sides of INF (denoted by INF-R and INF-L) were used to record the raw SEMG (denoted by $\mathrm{S}_{\mathrm{RAW}}(\mathrm{n})$ ) signals simultaneously. The sEMG signal was recorded from each swallowing task, i.e., normal swallowing (denoted by ST-1) and dry swallowing (denoted by ST-2). Due to the participants' variation factor of neck anatomy, the artifact that mostly comes from electrocardiograph (ECG) signal and interference noise could reduce information fidelity and lower the signal-to-noise ratio (SNR) of $\mathrm{S}_{\text {RAW }}(\mathrm{n})$. The ECG signal artifact arouses because the muscle groups are located near the neck area, particularly from INF-L and INF-R electrodes. The example of recorded $\mathrm{S}_{\mathrm{RAW}}(\mathrm{n})$ from four channels (SUP-L, SUP-R, INF-L, and INF-R) on dry swallowing task (ST-2) from post-stroke patients is shown in Figure 2. 

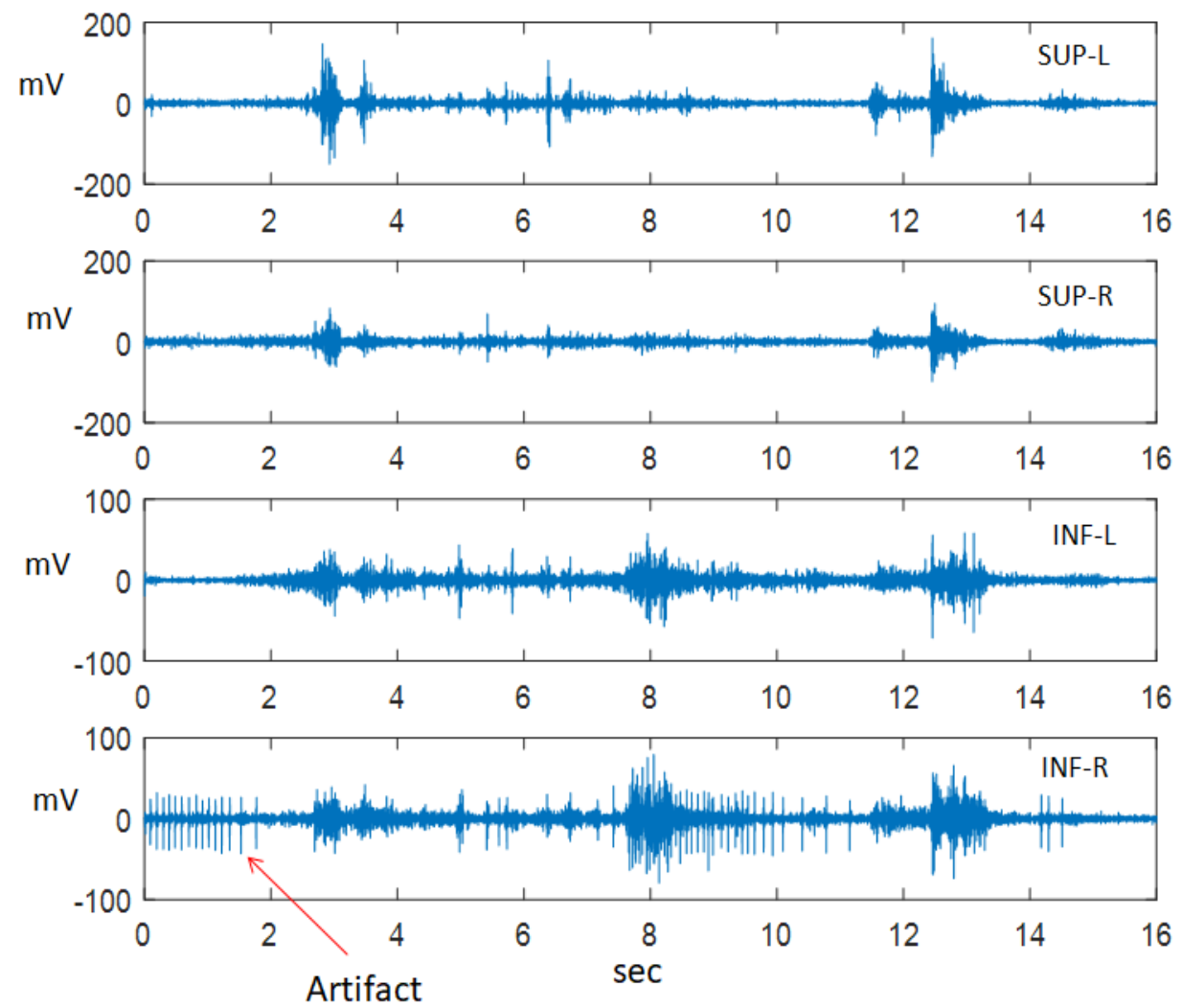

FIGURE 2. Recorded $\mathrm{S}_{\text {RAW }}$ (n) from three repetitions of dry swallowing task (ST-2). Noted that SUP-L = left suprahyoid, $\mathrm{SUP}-\mathrm{R}=$ right suprahyoid, and INF-L = left infrahyoid, $\mathrm{INF}-\mathrm{R}=$ right infrahyoid. The red arrow marks the typical ECG artifact on SRAW(n) from INF-R

Before the feature extraction of $S_{\text {RAW }}(n)$ in the time domain was performed, some signal processing steps were proposed. In this work, the first processing step was denoising and artifact suppression of $\mathrm{S}_{\mathrm{RAW}}(\mathrm{n})$, followed by the rectification and enveloping of $S_{\text {RAW }}(n)$. Then, the signal segmentation was done to focus on the complete muscle activity cycle during the swallowing process. On the final processing steps, the enveloped $\mathrm{S}_{\mathrm{RAW}}(\mathrm{n})$ (denoted by $S_{E}(n)$ ) was used to determine the features, i.e. the time to peak of maximum contraction (denoted by TTP), the contraction duration (denoted by DUR), and the total RMS power (denoted by TP).

\section{DENOISING AND ARTIFACT SUPPRESSION}

The example of $\mathrm{S}_{\text {RAW }}(\mathrm{n})$ recorded from muscle activities on dry swallowing task (ST-2) is shown in Figure 2. For denoising and artifact suppression of $\mathrm{S}_{\text {RAW }}(\mathrm{n})$, a method based on the discrete wavelet transform (DWT) was used. DWT processed $\mathrm{S}_{\text {RAW }}(\mathrm{n})$ with a multi-resolution level and basis wavelet function. This method could be tuned more flexibly to remove noise and artifacts in $\mathrm{S}_{\mathrm{RAW}}(\mathrm{n})$. The general process for cleaning $S_{\text {RAW }}(n)$ using DWT needs the selection of four parameters in these following processing steps: 1 . Selection of the wavelet basis function based on Daubechies's (dB45) and wavelet decomposition level $\mathrm{L}=5$. 2. The coefficient of DWT is selected for signal reconstruction. For sampling frequency, Fs $=2048$, the DWT coefficients at $\mathrm{L}$ have the specific frequency range of $0-0.5^{\mathrm{L}} \mathrm{f}_{\mathrm{m}}$ for $\mathrm{A}_{\mathrm{L}}(\mathrm{n})$ and $0.5^{\mathrm{L}} \mathrm{f}_{\mathrm{m}}-2\left(0.5^{\mathrm{L}} \mathrm{f}_{\mathrm{m}}\right)$ for $D_{L}(n)$. Removing a frequency range of $S_{\text {RAW }}(n)$ due to noise and motion artifact was considered to select DWT coefficients $\left\{\mathrm{A}_{5}, \mathrm{D}_{5}, \mathrm{D}_{4}, \mathrm{D}_{3}, \mathrm{D}_{2}, \mathrm{D}_{1}\right\}$ for $\mathrm{L}=5$. 3. Before reconstruction, these wavelet coefficients were selected using the 'sqtwolog' function, hard threshold, and removing noise estimation based on eliminating wavelet coefficients $\mathrm{A}_{5}, \mathrm{D}_{5}$, and $\mathrm{D}_{1}$. 4. The processing output (denoted by $\mathrm{S}_{\mathrm{F}}(\mathrm{t})$ ) was targeted to improve $\mathrm{SNR}$ of $\mathrm{S}_{\text {RAW }}(\mathrm{t})$ ) related to both SUP and INF muscle group activities. 
The example of typical denoised and artifact suppressed output $\left(\mathrm{S}_{\mathrm{F}}(\mathrm{n})\right)$ is illustrated in Figure 3 (top). The result demonstrated that the noise and ECG artifact in $\mathrm{S}_{\text {RAW }}(\mathrm{n})$ could be suppressed effectively using this approach.
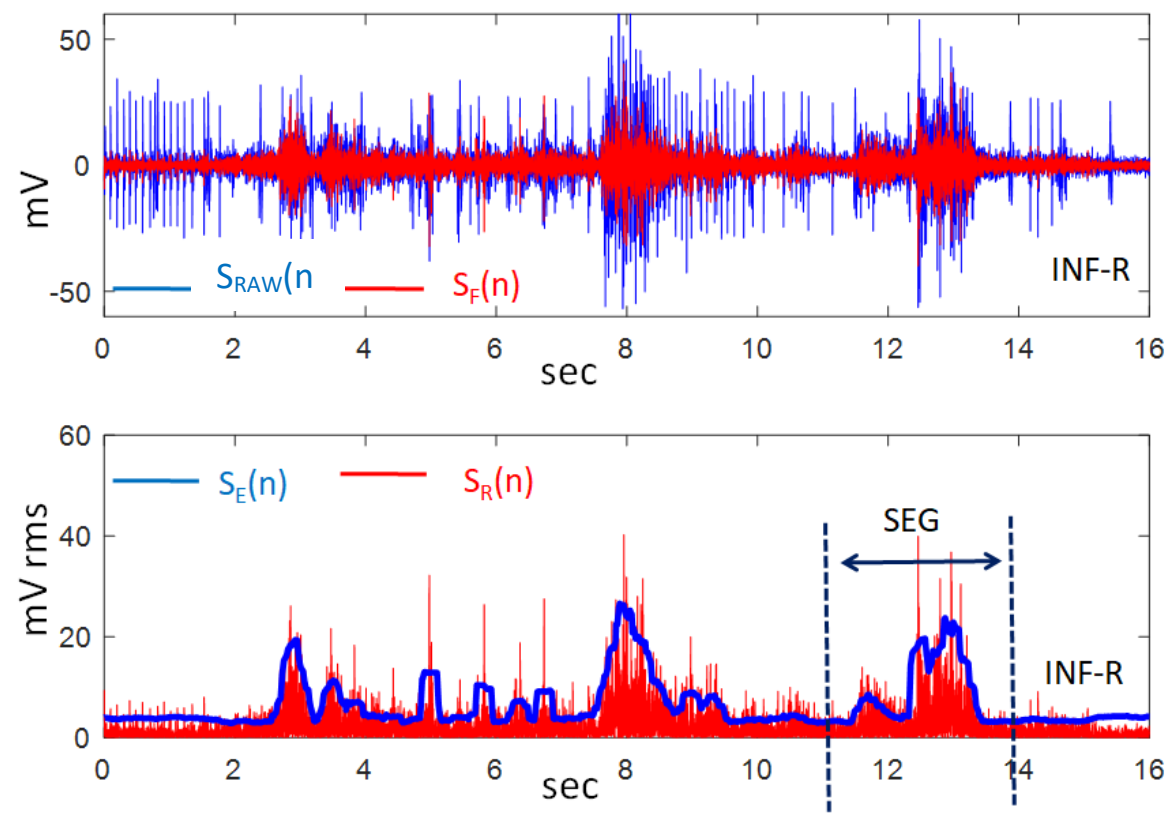

FIGURE 3. The illustration of the processing steps of $S_{\text {RAW }}(n)$ in post-stroke patients from electrodes INF-R. (Top) The output of denoised and artifact suppressed of $S_{\text {RAW }}(n)$ is denoted by $\mathrm{S}_{\mathrm{F}}(\mathrm{n})$. (Bottom) The rectified output $\left(\mathrm{S}_{\mathrm{R}}(\mathrm{n})\right.$ ) and enveloped output $\left(\mathrm{S}_{\mathrm{E}}(\mathrm{n})\right)$. The segmentation of $\mathrm{S}_{\mathrm{E}}(\mathrm{n})$ in the data length of $\mathrm{SEG}$ is used for sEMG feature extraction in the time domain

\section{RECTIFICATION AND ENVELOPING}

An amplitude of the sEMG signal (denoted by $\mathrm{S}_{\mathrm{F}}(\mathrm{n})$ ) has positive and negative polarity. As feature extraction was performed in the time domain of $\mathrm{S}_{\mathrm{F}}(\mathrm{n})$, a rectification process of $S_{F}(n)$ was required to identify the overall strength of the muscle groups (SUP and INF) during contraction. The rectification of $S_{F}(n)$ (denoted by $S_{R}(n)$ ) was used to reverse the polarity of the negative peaks into the positive peaks without losing the information of the time interval of EMG burst. The rectification of $\mathrm{S}_{\mathrm{F}}(\mathrm{n})$ was determined by:

$$
\mathrm{S}_{\mathrm{R}}(\mathrm{n})=\sqrt{\mathrm{S}_{\mathrm{F}}(\mathrm{n})^{2}}
$$

The enveloping process was started by setting the sliding window of length $w$ samples in $\mathrm{S}_{\mathrm{R}}(\mathrm{n})$. The signal envelope at the data points $n$ was determined by:

$$
S_{E}(n)=\frac{1}{N} \sum_{i=n-\frac{w}{2}}^{n+\frac{w}{2}} S_{R}(i) \cdot h(n-i)
$$

where $\mathrm{h}($.$) is the rectangular window; and \mathrm{N}$ is the number of point data in window length. Selection of the length of $w$ must consider two aspects of envelope shape prediction of $S_{R}(n)$, i.e.: 1 . Consistency of determining the start/endpoint of $S_{E}(n)$ under small fluctuation of background noise. 2. The envelope shape of $S_{E}$ (n) must accommodate a small fluctuation that may arise in a period of muscle contraction. The processing steps for rectification and enveloping of $\mathrm{S}_{\mathrm{F}}(\mathrm{n})$ were illustrated in Figure 3.

\section{SEGMENTATION}

Synchronizing muscle group activities of SUP-L, SUP-R, INF-L, and INF-R on each swallowing task (ST-1 and ST-2) were required to understand the quantification process better. The segmentation process was performed on $\mathrm{S}_{\mathrm{E}}(\mathrm{n})$. The additional information that must be considered for segmentation of $\mathrm{S}_{\mathrm{E}}(\mathrm{n})$, i.e.: 1. A timestamp corresponds to the initial time when the participant was 
given a command to perform a swallowing task. 2. For each swallowing task, three repetition task was performed. For the segmentation process, a period of task resulting in SE's best quality (n) was selected based on subjective criteria of clinical expertise. 3 . The segmentation window of $\mathrm{S}_{\mathrm{E}}(\mathrm{n})$ must cover a complete muscle activity period on each muscle group activity of SUP-L, SUP-R, INF-L, and INF-R. The denoising and artifact suppression processing is demonstrated in Figure 3 (top). At the same time, the illustration of the segmentation process in $\mathrm{S}_{\mathrm{E}}(\mathrm{n})$ on the defined period of $\mathrm{S}_{\mathrm{F}}(\mathrm{n})$ is shown in Figure 3 (bottom).

\section{FEATURE EXTRACTION}

Given the enveloped signal $\mathrm{S}_{\mathrm{E}}(\mathrm{n})$, the procedures that were used for feature extraction is described as follow: 1. The contraction duration (DUR) is the time from the increased amplitude of $\mathrm{S}_{\mathrm{E}}(\mathrm{n})$ (corresponding to the start (onset-ON) of the swallowing process) to the end (offset-OFF) of the swallowing process. Duration (DUR) is determined by subtraction offset-OFF relative to the onset-ON time point. 2. The time to peak (TTP) represents the time required by a muscle to reach its maximum contraction in one swallow. The maximum contraction is expressed as the maximum amplitude of the $S_{E}(n)$. The TTP of maximum contraction is the time required to reach maximum $S_{E}(n)$ relative to SE's onset-ON time point (n). 3. The total RMS power (TP) related to the contraction duration is defined as follow: a) Given window $w(\mathrm{n})$ related to the contraction duration. The value of $w(\mathrm{n})=0$ for $\mathrm{S}_{\mathrm{E}_{\mathrm{E}}}(\mathrm{n}) \leq \operatorname{Tr}$ and $w(\mathrm{n})=1$ for $\mathrm{S}_{\mathrm{E}}(\mathrm{n}) \geq \operatorname{Tr}$. (b) TP is defined by $\frac{1}{\mathrm{~N}} \sum_{\mathrm{N}} w(\mathrm{n}) \cdot \mathrm{S}_{\mathrm{E}}(\mathrm{n})$.

The illustration of feature extraction of $S_{E}(n)$, i.e., DUR, TTP, and TP, are shown in Figure 4. For each participant, the feature extraction of DUR, TTP, and TP was determined on each swallowing task (ST).
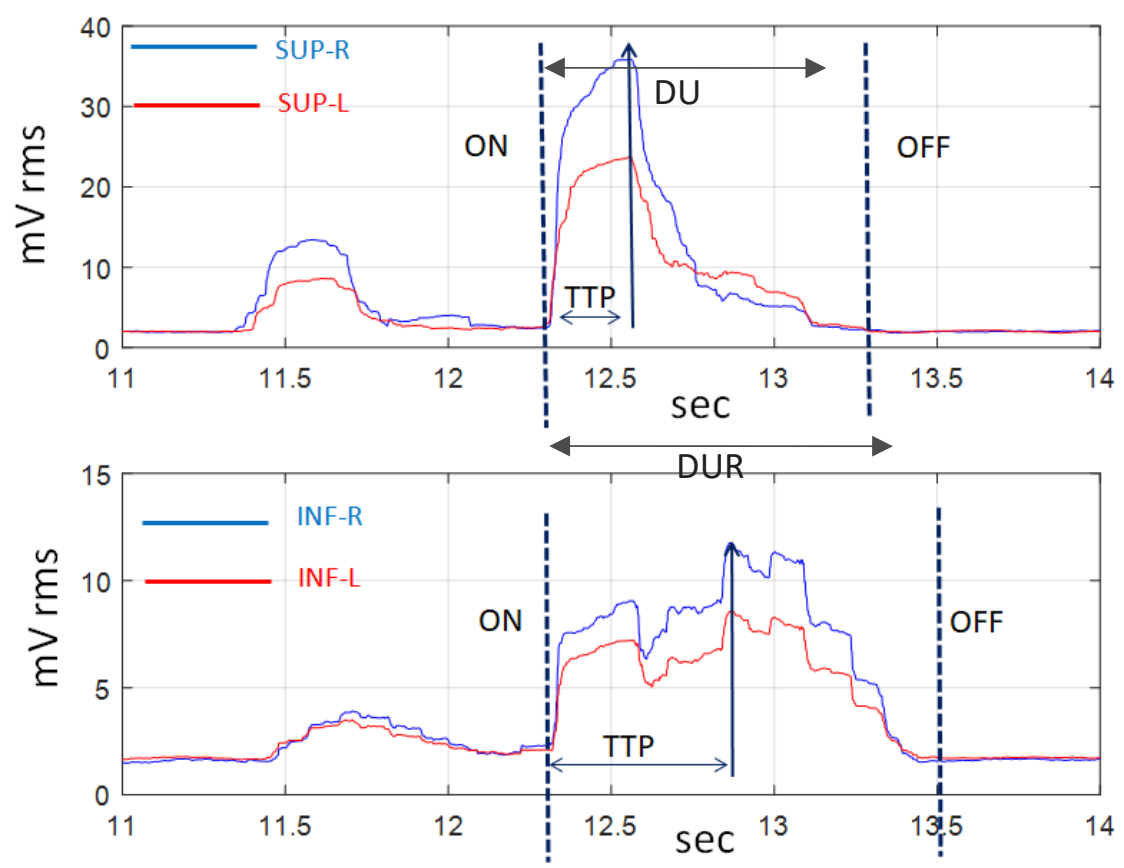

FIGURE 4. The features extraction process of $\mathrm{S}_{\mathrm{E}}(\mathrm{n})$ in the time domain, i.e. DUR, TTP, and TP. Note: the area represents TP under the curve of the signal

All formulation to compute the feature data set of DUR, TTP, and TP for each participant and ST are summarized in Table 1. For example, a data set of features DUR of each participant ni in case ST-1 and ST-2 is represented by $\left\{x \_D U R \_1 \_n i, y \_T T P \_1 \_n i, x \_T P \_2 \_n i\right.$, and y_TP_2_ni\}. Here, x_DUR_1_ni represents the average of the DUR from the SUP-L and the SUP-R. 
TABLE 1. Summary of features extraction of sEMG for each participant and swallowing task

\begin{tabular}{|c|c|c|}
\hline \multirow{4}{*}{$\begin{array}{l}\text { Feature extraction of sEMG for each } \\
\text { participant (ni) and swallowing task } \\
\text { (ST) }\end{array}$} & \multicolumn{2}{|c|}{ Swallowing task } \\
\hline & normal swallowing (ST-1) & dry swallowing (ST-2) \\
\hline & SUP muscle $=x$ & SUP muscle $=\mathrm{x}$ \\
\hline & INF muscle $=y$ & INF muscle $=y$ \\
\hline \multirow[b]{3}{*}{ Duration (DUR) for each participant: } & $\mathbf{x}_{- \text {DUR_1_ni }}=$ & $\mathbf{x}_{- \text {DUR_2_ni }}=$ \\
\hline & \{DUR 1 ni for SUP-L; & \{DUR 2 ni for SUP-L; \\
\hline & DUR_1_ni for SUP-R $\}$ & DUR_2_ni for SUP-R \\
\hline \multirow[t]{3}{*}{$\begin{array}{l}\text { X_DUR_ST_ni for SUP } \\
\text { Y_DUR_ST_ni for INF }\end{array}$} & $\begin{array}{c}\mathbf{y}_{- \text {DUR_1_ni }}= \\
\text { AVERAGE }\end{array}$ & $\begin{array}{c}\mathbf{y}_{- \text {DUR_2_ni }}= \\
\text { AVERAGE }\end{array}$ \\
\hline & $\{$ DUR_1_ni for INF-L; & \{DUR_2_ni for INF-L; \\
\hline & DUR_1_ni for INF-R \} & DUR_2_ni for INF-R\} \\
\hline \multirow[b]{3}{*}{$\begin{array}{l}\text { Time to peak (TTP) for each } \\
\text { participant: }\end{array}$} & $\begin{array}{l}\text { x_TTP_1_ni }= \\
\text { AVERAGE }\end{array}$ & $\begin{array}{c}\text { x_TTP_2_ni }= \\
\text { AVERAGE }\end{array}$ \\
\hline & $\left\{\mathrm{TTP} \_1 \_\right.$ni for SUP-L; & $\left\{\mathrm{TTP} \_2\right.$ ni for SUP-L; \\
\hline & TTP _1_ni for SUP-R & TTP_2_ni for SUP-R \\
\hline \multirow{4}{*}{$\begin{array}{l}\text { X_TTP_ST_ni for SUP } \\
\text { Y_TTP_ST_ni for INF }\end{array}$} & y_TTP_1_ni = & y_TTP_1_ni = \\
\hline & AVERAGE & AVERAGE \\
\hline & $\left\{\mathrm{TTP} \_1 \_\right.$ni for INF-L; & $\{$TTP_1_ni for INF-L; \\
\hline & TTP_1_ni for INF-R $\}$ & TTP_1_ni for INF-R $\}$ \\
\hline \multirow[b]{3}{*}{$\begin{array}{l}\text { Total RMS power }(\mathbf{T P}) \text { for each } \\
\text { participant: }\end{array}$} & $\begin{array}{l}\text { x_TP_1_ni = } \\
\text { AVERAGE }\end{array}$ & $\begin{array}{c}\text { x_TP_1_ni }= \\
\text { AVERAGE }\end{array}$ \\
\hline & \{TP_1_ni for SUP-L; & $\{$ TP_2_ni for SUP-L; \\
\hline & TP_1_ni for SUP-R & TP_2_ni for SUP-R \\
\hline \multirow{4}{*}{ 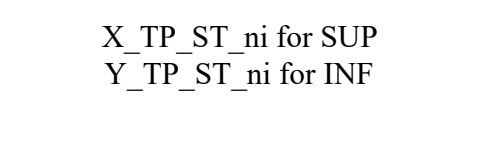 } & y_TP_1_ni $=$ & y_TP_2_ni $=$ \\
\hline & AVERAGE & AVERAGE \\
\hline & $\left\{\mathrm{TP} \_1 \_\right.$ni for INF-L; & $\{$TP_2_ni for INF-L; \\
\hline & TP_1_ni for INF-R\} & TP_2_ni for INF-R \} \\
\hline
\end{tabular}

\section{QUANTIFICATION PROCEDURE}

The quantification procedure for evaluating the proposed processing scheme to distinguish swallowing processes in healthy and patients is described as follows. The whole features data sets were processed for two primary group data related to healthy subjects and post-stroke patients.
The statistical analysis for two primary group data is summarized in Table 2, where each formulation of the mean $(\mu)$ and the standard deviation $(\sigma)$ of the features data from each participant (DUR, TTP, and TP) on each ST and muscle group are described. 
TABLE 2. Quantification process for each ST in SUP and INF muscle groups for all healthy subjects and post-stroke patients $(\mathrm{STDev}=$ standard deviation $)$

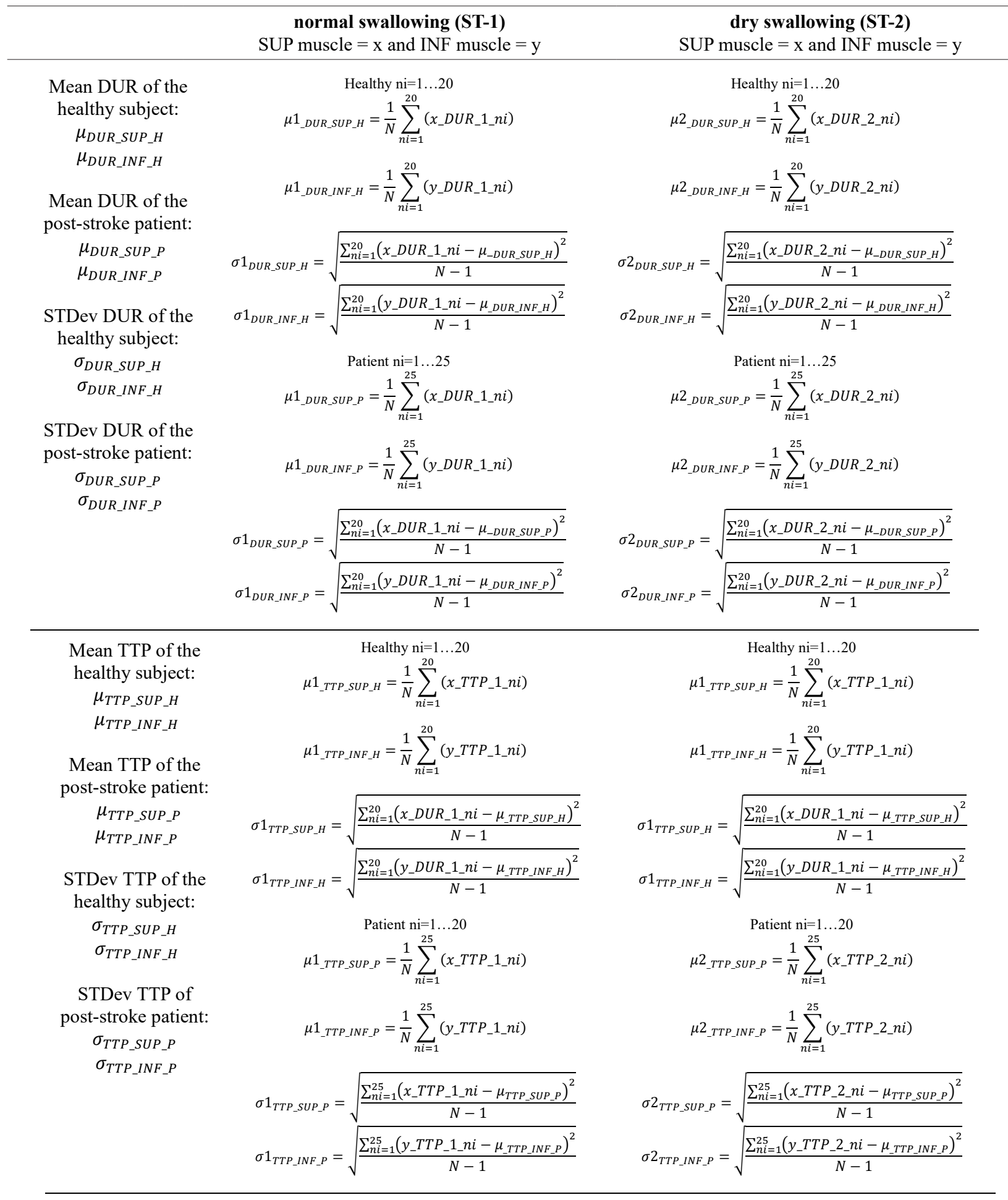




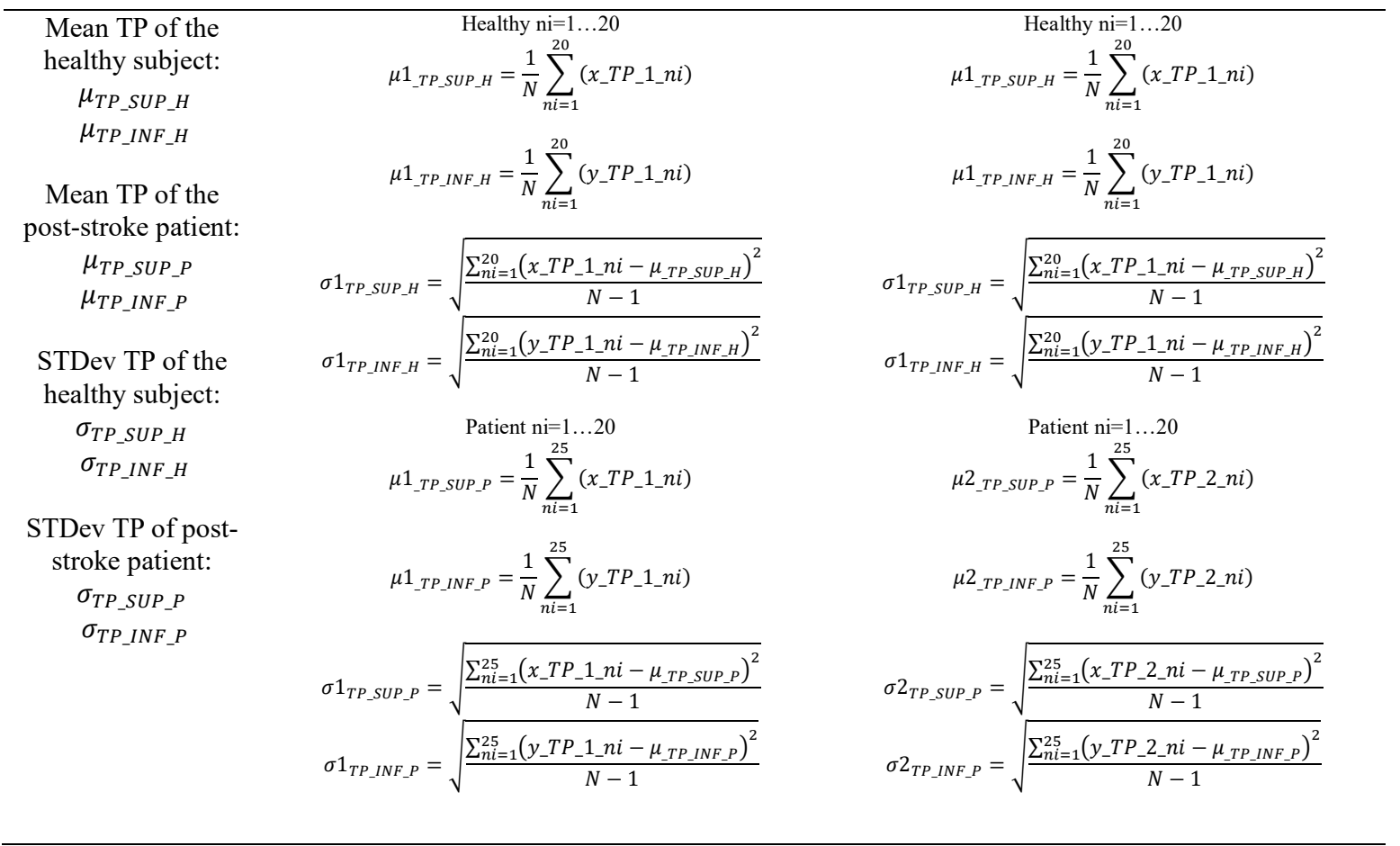

In the case of 20 healthy subjects, data analysis for feature DUR on ST- 1 could be written as $\{\mu 1$ DUR_SUP H $\pm \sigma 1 \_$DUR_SUP_H $\}$for SUP muscle group and $\left\{\mu 1 \_\right.$DUR INF_H $\pm \sigma 1$ DUR_INF_H $\}$ for INF muscle group. This procedure was also used for other feature data set and both group data related to post-stroke patients. Previous studies have reported no statistically significant sex-related differences in muscle duration during single swallowing (Koyama et al. 2021; Vaiman et al. 2004). Therefore, 20 sEMG data related to patients are quantification into one group set of data. The dissimilarity analysis of $\mu \pm \sigma$ determining the frame of each feature, ST, muscle group, and participant s group data was further evaluated in the following sections.

\section{RESULTS AND DISCUSSION}

\section{DURATION OF SWALLOWING PROCESS}

The swallowing duration is the time taken by a muscle group involved in the swallowing process to complete the swallowing phase and to contract to drain the drink from the oral cavity to reach the stomach. In this study, the swallowing duration was reviewed when the muscle groups involved in the oropharyngeal phase contract drained the fluid through the esophagus. In the oropharyngeal phase, the muscle groups actively contracting, i.e. SUP-L, SUP-R, INF-L, and INF-R. All data comparisons and analyses in this section are made via one-way analysis of variance (ANOVA) with a 0.05 significance level.

Figure 5 represents the analysis $\mu$ and $\sigma$ of DUR for healthy subjects and post-stroke patients. It has been found that healthy subjects have shorter DUR than post-stroke patients related to muscle groups (SUP and INF) and swallowing tasks (ST-1 and ST-2). It happened because the muscle function in patients has decreased due to the stroke that occurred, which affected the central nervous system's ability to carry out motor commands to the muscles involved in the swallowing process. The activity of the SEMG signal reflects the motor unit action potential (MUAP) by peripheral nerves. An increase in the duration of activation indicates prolonged peripheral nerve stagnation, resulting in prolonged muscle contraction. The longer duration of swallowing in post-stroke patients than in healthy subjects can be caused by continuous peripheral nerve stimulation and increased afferent nerve information (Wheeler et al. 2007). The central nervous system primarily controls the stimulation of peripheral nerves to activate muscle movement. There is a disturbance in the central nervous system in stroke patients, which is different in each 


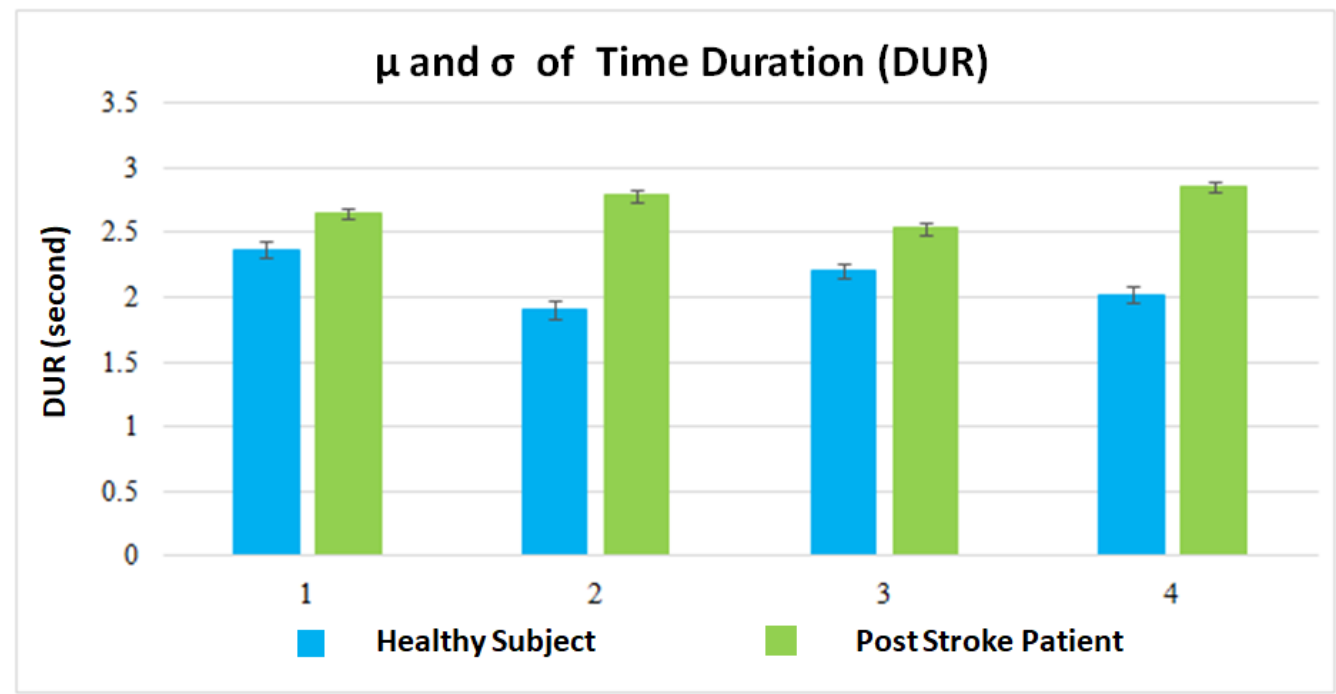

FIGURE 5. The $\mu$ and $\sigma$ of DUR of the two swallowing process tasks for suprahyoid (SUP) and infrahyoid (INF) muscle groups

$\mathbf{1}=\mathrm{ST}-1$ for SUP, $\mathbf{2}=\mathrm{ST}-1$ for INF, $\mathbf{3}=\mathrm{ST}-2$ for SUP, $\mathbf{4}=\mathrm{ST}-2$ for INF

location of the lesion or stroke type. Therefore, there is a high probability that peripheral nerves may be affected due to the stroke, which causes prolonged stimulation of the peripheral nerves or a time delay for the central nervous system to stimulate muscle contraction. In general, poststroke patients take longer to distribute drink from the oral cavity to the stomach that manifests on the $\mu \pm \sigma$ from the DUR data set.
THE TIME TO PEAK (TTP) OF SWALLOWING PROCESS

The analysis of $\mu$ and $\sigma$ from the TTP data set for healthy subjects and patients is represented in Figure 6. In general, the TTP data sets of healthy subjects were shorter than the TTP data sets of post-stroke patients. It indicated that healthy subjects are faster in achieving maximum contraction of muscles involved in the swallowing process.

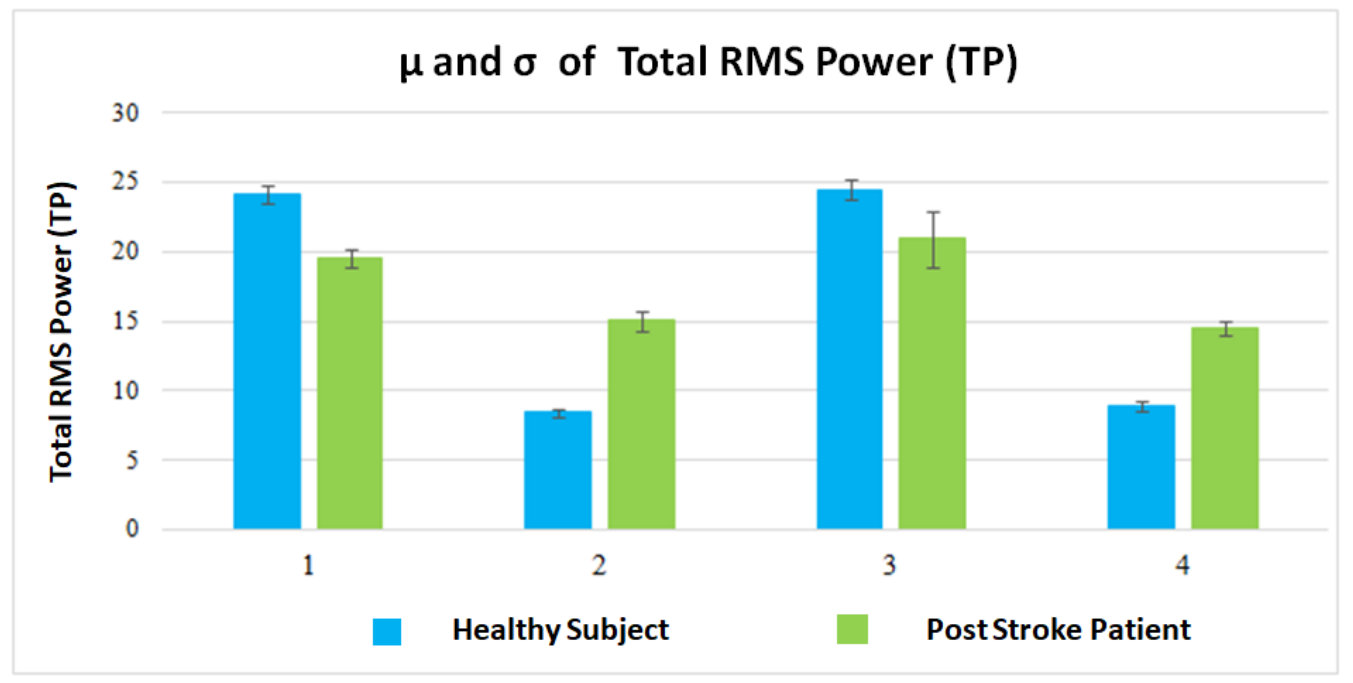

FIGURE 6 . The $\mu$ and $\sigma$ of TTP of the two swallowing process tasks for suprahyoid (SUP) and infrahyoid (INF) muscle groups

$\mathbf{1}=$ ST-1 for SUP, $\mathbf{2}=$ ST-1 for INF, $\mathbf{3}=$ ST- 2 for SUP, $\mathbf{4}=$ ST-2 for INF 
THE TOTAL RMS POWER (TP) OF THE SWALLOWING PROCESS

The TP of the enveloped sEMG signal $\left(\mathrm{S}_{\mathrm{E}}(\mathrm{n})\right)$ represents the muscle energy used for the swallowing process related to specific DUR on each participant and swallowing task (ST-1 and ST-2). The analysis of $\mu \pm \sigma$ from the TP data set for healthy subjects and post-stroke patients is represented in Figure 7. It has been found that $\mu \pm \sigma$ from the TP data set related to the SUP muscle group was higher than the INF muscle group, both for healthy subjects and post-stroke patients. The higher amplitude of the TP data reflects an increase in the unit motor's discharge rate or an increase in the number of motor units recruited (Wheeler et al. 2007). More muscle fibers in healthy subjects carry out the swallowing process in the SUP muscle group. Physiologically, the SUP and INF muscle groups work together in elevating the larynx and hyoid. However, it has been found that $\mu \pm \sigma$ from the TP data set related to the INF muscle group in healthy subjects was smaller than TP data in post-stroke patients. The result indicated that only the SUP muscle group was required to hold the larynx in an elevated position during the swallowing process (Ding et al. 2002). Furthermore, this also indicated that the SUP muscle group has a more significant role than the INF muscles in the swallowing process.

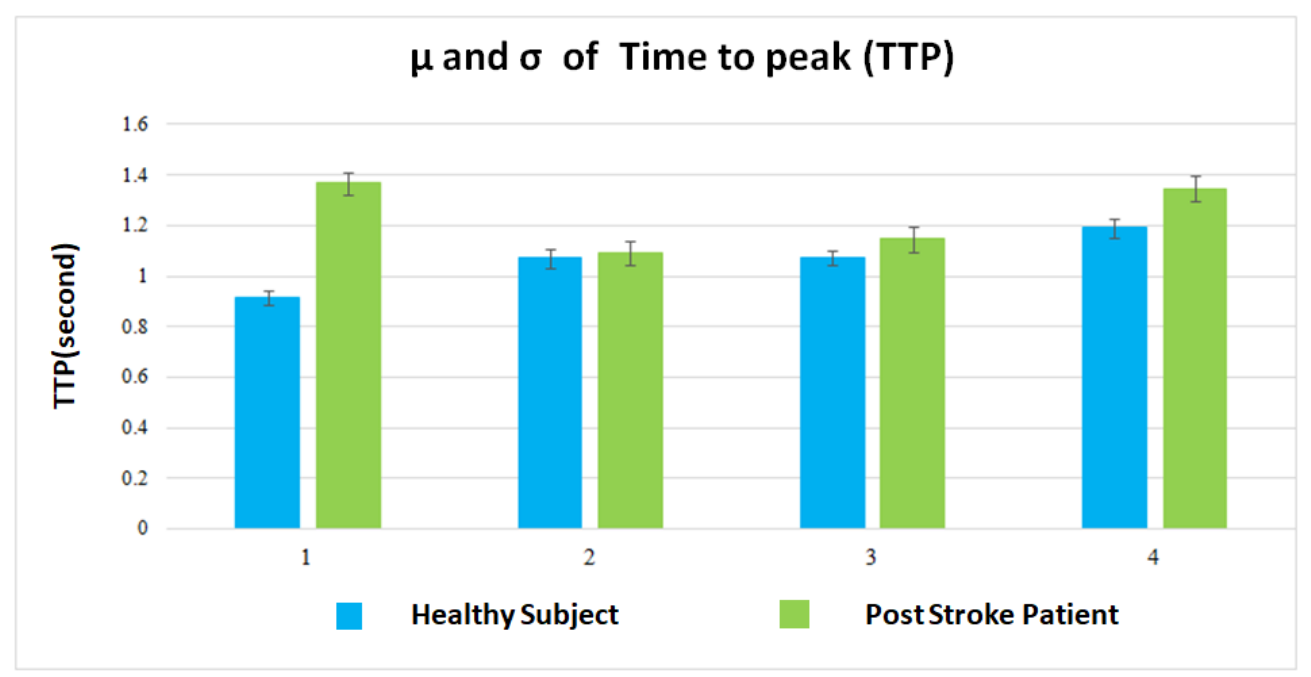

FIGURE 7. The $\mu$ and $\sigma$ of TP of the two swallowing process tasks for suprahyoid (SUP) and infrahyoid (INF) muscle groups.

$\mathbf{1}=$ ST-1 for SUP, $\mathbf{2}$ = ST-1 for INF, $\mathbf{3}$ = ST-2 for SUP, $\mathbf{4}=$ ST-2 for INF

\section{CONCLUSION}

The proposed signal processing procedure is useful to establish the feature extraction of the contraction duration (DUR), the time to peak of maximum contraction (TTP), and the total RMS power (TP). This has been proven to be successful in evaluating the swallowing process. From the evaluation of 20 healthy subjects and 20 post-stroke patients, it has been found that DUR on healthy subjects was shorter than on post-stroke patients. These results are consistent for suprahyoid (SUP) and infrahyoid (INF) muscle groups for both normal swallowing (ST-1) and dry swallowing (ST-2). A similar characteristic has also been found to the peak maximum contraction (TTP) feature of the SUP and the INF muscle groups. For dysphagia assessment, with the support of our proposed signal processing procedure, DUR and TTP features may be used together to improve diagnosis reliability. The TP feature is useful as additional information for evaluation related to SUP and INF muscle groups' role in the healthy subjects and post-stroke patients. In general, it has been found that the TP of the SUP muscle group was higher than the TP of the INF muscle group for both healthy subjects and poststroke patients. However, from the statistical analysis, the TP data related to the INF muscle group in healthy subjects were proven to be smaller than the TP data in post-stroke patients. This result indicates that the SUP muscle groups have a more significant role than the INF muscle groups during the swallowing process in a normal condition. 
To conclude, all of these findings are very promising in providing a set of reliable features in the time domain. This is mainly useful for supporting the development of an automatic classification system for dysphagia diagnosis. However, the proposed quantification methods have limitations. The main problem is recording sEMG on the patients with good SNR sEMG signal for further processing. The problem may arise due to the variation factor of neck anatomy and the typical size of sEMG electrodes. In future work, the limitation of quantification methods could be reduced with a specific design of flexible sEMG electrodes that matched with a specific neck anatomy area.

\section{ACKNOWLEDGEMENTS}

We would like to thank the Program of Research, Community Service, and Innovation of Institut Teknologi Bandung (P3MI-ITB) year 2020 for providing the funding for this research.

\section{REFERENCES}

Archer, S.K., Smith, C.H. \& Newham, D.J. 2020. Surface electromyography biofeedback and the effortful swallow exercise for stroke-related dysphagia and in healthy aging. Dysphagia 36(2): 281-292.

Baroni, A.F.F.B., Fabio, S.R.C. \& Dantas, R.O. 2012. Risk factors for swallowing dysfunction in stroke patients. Arquivos de Gastroenterologia 49(2): 118-124.

Benfield, J.K., Everton, L.F., Bath, P.M. \& England, T.J. 2020. Accuracy and clinical utility of comprehensive dysphagia screening assessment in acute stroke: A systematic review and meta-analysis. Journal of Clinical Nursing 29(9-10): 1527-1538.

Ding, R., Larson, C.R., Logemann, J.A. \& Rademaker, A.W. 2002. Surface electromyographic and electroglottographic studies in normal subjects under two swallow conditions: Normal and during the Mendelsohn maneuver. Dysphagia 17(1): 1-12.

Edmiaston, J., Connor, L.T., Steger-May, K. \& Ford, A.L. 2014. A simple bedside stroke dysphagia screen, validated against videofluoroscopy, detects dysphagia and aspiration with high sensitivity. Journal of Stroke \& Cerebrovascular Diseases 23(4): 712-716.

Giannantoni, N.M., Minisci, M., Brunetti, V., Scarano, E., Testani, E., Vollono, C., De Corso, E., Bastanza, G., D'Alatri, L. \& Della Marca, G. 2016. Evaluation of pharyngeal muscle activity through nasopharyngeal surface electromyography in a cohort of dysphagic patients with acute ischaemic stroke. Acta Otorhinolaryngologica Italica 36(4): 295-299.

Kim, D.Y., Park, H.S., Park, S.W. \& Kim, J.H. 2020. The impact of dysphagia on quality of life in stroke patients. Medicine (Baltimore) 99(34): e21795.
Koyama, Y., Ohmori, N., Momose, H., Kondo, E., Yamada, S.I. \& Kurita, H. 2020. Detection of swallowing disorders using a multiple channel surface electromyography sheet: A preliminary study. Journal of Dental Sciences 16(1): 160-167.

Miyashita, T., Kikutani, T., Nagashima, K., Igarashi, K. \& Tamura, F. 2020. The effects of sarcopenic dysphagia on the dynamics of swallowing organs observed on videofluoroscopic swallowing studies. Journal of Oral Rehabilitation 47(5): 584-590.

Pacheco-Castilho, A.C., Vanin, G.D.M., Dantas, R.O., PontesNeto, O.M. \& Martino, R. 2019. Dysphagia and associated pneumonia in stroke patients from Brazil: A systematic review. Dysphagia 34(4): 499-520.

Rommel, N., Borgers, C., Beckevoort, D.V., Goeleven, A., Dejaeger, E. \& Omari, T.I. 2015. Bolus residue scale: An easy-to-use and reliable videofluoroscopic analysis tool to score bolus residue in patients with dysphagia. International Journal of Otolaryngology 2015: 780197.

Saijo, R., Saotome, K., Jayatilake, D. \& Suzuki, K. 2017. EMG signals-based modeling of the initial phase of the swallowing process. In 2017 8th International IEEE/EMBS Conference on Neural Engineering (NER). IEEE. 78-81.

Saitoh, E., Pongpipatpaiboon, K., Inamoto, Y. \& Kagaya, H. 2018. Dysphagia Evaluation and Treatment: From the Perspective of Rehabilitation Medicine. Gateway East, Singapore: Springer Nature.

Sreedharan, S.E., Sayed, J.V., Vipina, V.P., Mohan, M.P., Paul, R. \& Sylaja, P.N. 2020. Dysphagia and disability in minor strokes: An institutional study. Journal of Stroke and Cerebrovascular Diseases 29(9): 105070.

Umay, E., Eyigor, S., Karahan, A.Y., Gezer, I.A., Kurkcu, A., Keskin, D., Karaca, G., Unlu, Z., Tikiz, C., Vural, M., Aydeniz, B., Alemdaroglu, E., Bilir, E.E., Yaliman, A., Sen, E.I., Akaltun, M.S., Altindag, O., Keles, B.Y., Bilgilisoy, M., Ozcete, Z.A., Demirhan, A., Gundogdu, I., Inanir, M. \& Calik, Y. 2019. The GUSS test as a good indicator to evaluate dysphagia in healthy older people: A multicenter reliability and validity study. European Geriatric Medicine 10(6): 879-887.

Wheeler, K.M., Chiara, T. \& Sapienza, C.M. 2007. Surface electromyographic activity of the submental muscles during swallow and expiratory pressure threshold training tasks. Dysphagia 22(2): 108-116.

Vaiman, M., Eviatar, E. \& Segal, S. 2004. Evaluation of normal deglutition with the help of rectified surface electromyography records. Dysphagia 19(2): 125-132.

Suprijanto*, Azizah S. Noor \& Hesty Susanti

Medical Instrumentation Laboratory

Instrumentation and Control Research Group

Faculty of Industrial Technology

Institut Teknologi Bandung

Indonesia 
Miranti I. Mandasari

Department of Engineering Physics

Faculty of Industrial Technology

Institut Teknologi Bandung

Indonesia
*Corresponding author; email: supri@tf.itb.ac.id

Received: 21 November 2020

Accepted: 19 April 2021 